\title{
2014
}

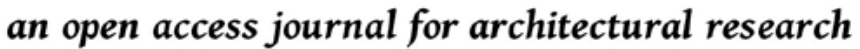

volume 11 | issue 1

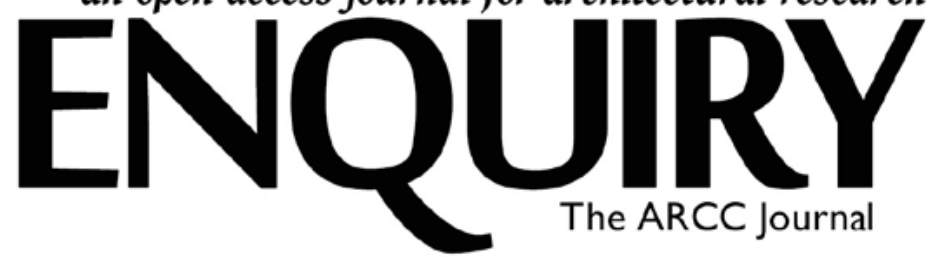

\section{MATERIAL AND SOCIAL CONSTRUCTION: A FRAMEWORK FOR THE ADAPTATION OF BUILDINGS}

Jesse M. Keenan

\begin{abstract}
This article is a formulation of a framework for understanding the nature of change, particularly climate change, as it applies to the scale of a building. Through an exploration of various scientific and social scientific literature, the article positions the concept of adaptation as the appropriate mode for understanding and managing change. Through the classification of a duality of material and social construction in the ontological composition of a building, various lines of thought relating to adaptive capacity and adaptive cycling within systems theory are appropriated within an integrated framework of adaptation. Specifically, it is theorized that as buildings as objects are developing greater capacities for integrated operations and management through artificial intelligence, they will possess an ex ante capacity to autonomously adapt in dynamic relation to and with the ex post adaptation of owners and operators. It is argued that this top-down and bottom-up confluence of multi-scalar dynamic change along an adaptive cycle is consistent with the prevailing Theory of Panarchy applied in social-ecological systems theory. The article concludes with perspectives on the limitations of systems theory in architecture, future directions for research and an alternative positioning of professional practices.
\end{abstract}

\section{Permissions and copyright}

Authors retain copyright and grant the journal right of first publication with the work simultaneously licensed under a Creative Commons Attribution License that allows others to share the work with an acknowledgement of the work's authorship and initial publication in this journal (Attribution-ShareAlike).

Creative Commons Attribution 3.0 Unported (CC BY 3.0)

You are free to: Share - copy and redistribute the material in any medium or format. Adapt - remix, transform, and build upon the material for any purpose, even commercially. The licensor cannot revoke these freedoms as long as you follow the license terms.

Under the following terms: Attribution - You must give appropriate credit, provide a link to the license, and indicate if changes were made. You may do so in any reasonable manner, but not in any way that suggests the licensor endorses you or your use.

No additional restrictions - You may not apply legal terms or technological measures that legally restrict others from doing anything the license permits.

How to cite:

Keenan, Jesse M. 2014. "Material and Social Construction: A Framework for the Adaptation of Buildings." Enquiry 11 (1): 18-32.

\section{INTRODUCTION}

The advent of climate change has accelerated the development of scientific and social scientific research into understanding the dynamic nature of change by and between complex systems and institutions. In a parallel state of paralysis and development, architectural design research on the implications of climate change has largely been subservient in its relevance and application to the economic behaviors of the responsive modes of real estate production (Hertin et al. 2003; Stern 2007). In a limited capacity to-date, architectural design has been a proxy engagement for the incorporation of mono-technical solutions which serve to mitigate the occurrence of climate change justified through operational economic efficiencies (Etzion et al. 1997; Givoni 1998; Steemers 2003; Van der Linden et al. 2006; Schuetz 2011; Brown and Dixon 2014). Yet, in the face of climate change, the construction of architecture's aesthetic and semiotic power has the ability to preserve and advance forms of culture which escape economic unitization. As such, the conventional mitigation framework-often co-referenced as sustainabilityis increasingly reaching a threshold of comprehensiveness, influence and development as climate change is now unstoppable by human action (International Panel on Climate Change (IPCC) 2014).

This article proposes a normative framework from which future theoretical and empirical research can advance the practice of designing and managing adaptive buildings. This framework is intentionally limited to the scale of the building and its users and not to the urban form, which has a different range of calculi and associated sets of methods and ontologies (Vachon et al. 2013). This limitation of scale does not exclude from analysis the natural and urban ecological forces which shape the use and performance of a building. Instead, it merely acknowledges that the systems behind such forces have separate and unique capacities and cycles to accommodate change, even if such capacities and cycles are reciprocally dependent in some measure on the design and operations of a building.

Inherent in this exercise is an acknowledgment that the problem- 
solution set cannot be entirely optimized or engineered given the socio-ecological complexity of the challenges which are yet to be known (Bulkeley and Betsill 2013; Mazmanian et al. 2013; Ovink 2014). As such, adaptation at the scale referenced herein is a set of dynamic multi-scalar systematic processes which are referenced to a variety of stimuli that are not exclusively physical, ecological or climatic in their proximate degrees of influence. By extension, this adaptation framework is developed not as an exercise for explaining change but as a means of understanding and exploring the balancing of design intentions and management strategies which may be both anticipatory and reactive. From accommodating an aging society in Tokyo multifamily buildings to flood proofing commercial office buildings in New York City, a comprehensive framework for adaptive building design and management which bridges various scales, typologies and stimuli has yet to be explored.

The first step in the development of this nascent framework is the positioning of the concept of adaptation by and between a diverse set of competing and interrelated concepts which have specific distinctions relating to actor orientation, time horizon, and system dynamics. Through the classification of a duality of material and social construction in the ontological composition of a building, various lines of thought relating to adaptive capacity and adaptive cycling within systems theory are appropriated within an integrated framework of adaptation. Specifically, it is theorized that as buildings as objects are developing greater capacities for integrated operations through machine learning and the artificial intelligence of building systems, they will possess a capacity to autonomously adapt in dynamic relation to and with the adaptive capacity of managers and users. While building managers and users tend to adapt to stimuli after the occurrence of the stimuli (i.e., ex post), the artificial intelligence of adaptive building systems allows for the buildings as objects to possess a capacity based on both internal and external designs which can accommodate change at the time of or prior to the occurrence of various stimuli (i.e., ex ante). It is argued that this confluence of multi-scalar dynamic change which has the capacity to result in the realized adaptation of a building is consistent with the prevailing Theory of Panarchy applied in social-ecological systems theory. The article concludes with perspectives on the limitations of systems theory in architecture, future directions for research and an alternative positioning of professional practices.

\section{METHODOLOGY}

This exploratory and qualitative research is primarily based on a comprehensive literature review of both the science of adaptation and the science for adaptation within a variety of science and social science domains (Swart et al. 2014). To fill in the gaps between these external domains of theory and practice and that of architecture, select interviews were initially undertaken with practicing architects, landscape architects, urban designers and associated academics who teach adaptation- and resiliencebased studios. The fifteen $(n=15)$ interviews were semi-structured with a duration of approximately one hour and were conducted with faculty primarily teaching in the New York metropolitan area. Inquiries were made about the interviewee's experience in sustainable, resilient and adaptive designs and whether there was any operable knowledge in defining and distinguishing between these concepts, as well as whether any distinctions were ripe, necessary or relevant. The outcome of the research was consistent with the initial assumptions which motivated the production of this research. First, there was no consistency in the application of any of the concepts of mitigation, coping, resiliency and adaptation. However, all fifteen interviewees were able to correctly define mitigation as applied to either climate mitigation or hazard mitigation, but only five interviewees found common meaning between the two applications. When inquiry was made as to how these concepts applied in decisions within their professional practices, seven interviewees acknowledged that the primary impetus after Hurricane Sandy was rebuilding the status quo and that resiliency was largely a rhetorical device which cannot be meaningfully separated from risk mitigation. Thereafter, there was no definitional consistency, even for those who additionally practiced in environmentally sensitive geographies following the occurrence of Hurricane Sandy.

As such, the collection and interpretations of the data after Hurricane Sandy may be subject to certain convenience and availability biases (Nicholls 1999; Sunstein 2006). This is to say that the risks of flooding may impose a narrow frame of reference in terms of timing and response which biases a larger world view on climate change or any other social, environmental or economic stimuli. The categorical results of the interviews are not presented in this article, but the disparate nature of the results: (i) reinforced the timeliness of the necessity to draw order by and between the concepts presented herein; and, (ii) contextualized the necessity to give a hierarchy of motivations (i.e., real preference for mitigation) by and between the concepts of response. As a consequence of this multi-method research design, it should be qualified that the truth of the existence of any framework as a higher ordering acknowledgment of actual phenomena by agents of artificial or natural intelligence can only be evaluated through the eyes of history and therefore escapes empirical confirmation and falsification short of critical theoretical validation. However, with the proliferation of the adaptive technologies described herein, there exists an opportunity in the future to empirically evaluate the framework of this article as applied in professional practice.

\section{UNDERSTANDING CONCEPTS OF CHANGE}

There exists today a great deal of variation in the meanings and heuristics assigned to a variety of concepts which address the nature of a response to change (Moser and Ekstrom 2010; Preston et al. 2013). The distinction and definitional or conceptual consistency between the terms adaptation, mitigation, resiliency and coping is a practical hurdle to framework development in a variety of applied domains. This article attempts to assign order to these various concepts with the intent of positioning adaptation as the most appropriate concept with reference to 
the design and management of buildings. More specifically, it is acknowledged that the adaptation of buildings represents a duality of material (i.e., object) and social construction (i.e., managers/users) which creates a transient ontology from which science and social science applications of the foregoing concepts may be referenced.

Specific to climate science, adaptation is defined as the "adjustment in natural or human systems in response to actual or expected climatic stimuli or their effects, which moderates harm or exploits mutual opportunities" (IPCC 2007a, p. 869). A more comprehensive definition of adaptation "involve[s] both building adaptive capacity thereby increasing the ability of individuals, groups, or organizations to adapt to changes, and implementing adaptation decisions, i.e., transforming that capacity into action" [emphasis added] (Adger et al. 2005, p. 78). As discussed in the following section, the notion of capacity within the adaptation framework is critical to contextualizing the duality of building as an object and as a social construction.

As Uittenbroek et al. highlight, adaptation specific to climate change can be further categorized as a matter of governance versus process (i.e., specific measures) (2013). This is to say that adaptation may be an outcome of an active and willful intention, as well as a passive set of processes disconnected from deliberate manipulation. While resilience can be thought of as a preservation of the entire operations of the status quo of a host (a host may be an individual, a building, a community, an organization, etc.), adaptation is a gradual process of maintaining periodic points of resilience which ultimately results in a future state of being which is superior to its predicated state in its ability to flexibly respond and continue to be resilient to known and unknown external stimuli through, if necessary, a transformation of domains of operations. As such, resilient hosts revert to the status quo with a minimal change in their internal operations based on existing internal designs, while adaptation results in a superior post-stimuli state based on both internal and external designs. In this sense, adaptation can be defined as having the potential for transformability of the host to an entirely different state of operations (i.e., program, use, intensity of use, services, etc.). The implications for this are not without costs, as transformation may not always be a smooth transition. Likewise, a host may become resilient to a specific stimulus, but it does adapt if it cannot become resilient to slightly, dramatically or totally different sets of stimuli. Therefore, resilience and adaptation are closely related in that resilience is an internal process of adaptation along with mitigation and coping but each concept differs in its future states of being and its longterm implications in response to a diversity of stimuli (Nelson et al. 2007; Nelson 2011). In comparison, the following concepts each have their own criteria for occurrence, frequency, novelty and timing of stimuli (e.g., risks and opportunities) and their associated modes of response.

Mitigation holds perhaps the clearest conceptual distinction in that it speaks to the prevention of the occurrence of the external stimuli of change. Mitigation is often used interchangeably to mean hazard mitigation or climate mitigation (i.e., preventing hazards or climate change from happening at all or otherwise reducing the vulnerability to the risk). However, climate mitigation is increasingly losing relevancy as an exclusive matter of focus in that there is little doubt as to the long-term occurrence of climate change. It should also be acknowledged that many acts of adaptation are also acts of mitigation and they may not easily be separated. For instance, adding a flood barrier in a building may prevent the risk of flash flooding but may also promote adaptation to sea level rise if storm surge is more frequently putting the building at risk. However, mitigation and adaptation may also work against each other, with the classic example being that increased urban densities promote climate mitigation but make adaptation more difficult (McEvoy et al. 2006).

In contrast, coping is a short-term responsive mechanism for the preservation of the minimum operations of a host. Coping is very often utilized in a post-disaster context with the notion of rebuilding and recovery. This should be contrasted with resilience, which seeks to maintain all of the operations of the host in the face of present stimuli based on internal designs. Coping has no internal design to respond to the same stimuli in order to maintain its full operations and therefore is relegated to the process of maintaining minimal operations. Coping is a concept originally borrowed from the field of psychology, which evaluated individuals' ability to manage non-routine occurrences that are otherwise novel to the experience of the individual (Lazarus and Folkman 1984, p. 131). While the provision of emergency shelter and post-disaster psychological and financial counseling are laudable reactions to once-in-a-lifetime disasters, coping can very often be grounded in an emotional response with its own rationality that often conflicts with the long-term logics of adaptation. For instance, rebuilding a home which has been repeatedly flooded may serve to advance the coping of the residents but it does not serve to promote either resilience or adaptation. While an on-site flood barrier for these same homes may promote mitigation and resilience, it is unlikely to be an act of adaptation.

Again, in this scenario, an act of mitigation may or may not be an act of adaptation. Klein et al. make three major distinctions between mitigation and adaptation. First, as a function of time and scale, adaptation has long-term impacts distributed across a larger scale (i.e., global warming), with mitigation generally having an impact over a shorter time horizon on a more localized scale (Klein et al. 2005, p. 4). Second, citing the IPCC (2001a), they note that because of the two different scale and time horizons the costs and benefits to be "determined, compared and aggregated" differ (ibid.). Finally, the sectorial distinction between actors and interests is highlighted as a matter of administration and policy creation. The authors acknowledge the IPCC's ambition to optimally mix mitigation and adaptation strategies, but they note that variable interests (Lempert and Schlesinger 2000), 
actors (IPCC 1996) and methods (i.e., cost-benefit analysis, costeffective analysis, tolerable windows approach, game theory and multi-criteria analysis) (IPCC 2001b) make optimization an almost impossible task with very little academic or professional consensus.

In comparison to coping, which is oriented towards a single and unique stimulus, resiliency as a responsive concept represents a systemized reaction to singular or ongoing stimuli whether known, unknown or otherwise anticipated based on internal designs. In predicate biological terms, the scholarship of resiliency can be traced to the field of ecology which attempted to move beyond static understanding of the equilibrium of ecological systems in favor of transient systems which explain evolutionary processes that result in either change or extinction (Holling 1973). As applied in an economic context, resilience has been defined as, "the ability to dynamically reinvent business models and strategies as circumstances change. Strategic resilience is not about responding to onetime crises or rebounding from a setback. It's about continually anticipating and adjusting to [change]" (Hamel and Valikangas 2003, p. 52). In its broadest sense, resilience can be defined as, "a multidimensional, sociotechnical phenomenon that addresses how people, as individuals or groups, management uncertainty" (Lee et al. 2013, p. 29). However, it could be argued that the uncertainty could be further refined to mean a state of unawareness of either the timing or depth of some occurrence that is within the realm of possibility or probability. For example, resilience to a catastrophic meteorite strike is a matter of luck and not managed process. Of course, the randomness assigned to "luck" could virtually apply to all outcomes; but, the process of managed resilience can at least have a measurable reduction in risk to reduce the negative implications of random events either happening at all or otherwise negatively impacting a specific host. To this end, many scholars have questioned the extent to which resilience can be distinguished from adaptation in their parallel efforts to maintain operational functions by virtue of a managed or developed flexibility (ibid., p. 30).

The most useful performance traits of measuring resilience and adaptation-as borrowed from systems and computational theory-are robustness and reliability (Laprie 2008). Citing Anderson, Laprie defines robustness as a system's "ability to deliver service in conditions which are beyond its normal domain of operation" (Anderson 1988). From the perspective of computational theory, there are at least some conceptual distinctions between adaptation and resilience. First, resilience is often framed in a host's degree of robustness in its response as a matter of internal design, whereas adaptation may result in occurrence failure (or, some degree of failure) but may change for the next subsequent occurrence through the import of external designs (Woods and Wreathall 2008; Vogus and Sutcliffe 2007). This is often described as the transformability function of adaptation. Second, resilience is additionally defined by its time horizon and depth of impact. As noted by Wiggins:
Resilience and adaptation are not identical. No system can be 100 percent resilient to all changes; there will be a threshold where it breaks down. Beyond that threshold, adaptation is the only option. For example, climate change is projected to cause sea-level rise that will submerge some communities. Those communities would have no option but radical transformation-the scale of change would be beyond the resilience threshold where they could maintain their fundamental structures and functions. Also, adaptation has to be concerned with changes over 20, 50 or 100 years, not just the short term.

(2009, p. 79)

For as much literature as is cited herein, there is an equal or greater number of scholarly works which conflate the language of coping, resiliency and adaptation. This raises the pragmatic question as to whether the distinction is indeterminate of the modes of analysis and/or evaluation of system or host responsiveness. This research focuses on adaptation as it represents the appropriate localized scale of buildings which are anticipated to face continued novel and expected stimuli occurring as a consequence of climate change. While these concepts are interrelated within a meta-application of adaptation, a concise categorical distinction between adaptation, resilience, mitigation and coping is useful when evaluating specific responsive actions at various scales by various hosts within the built environment. For instance, interviews have suggested that community planning groups and politicians are primarily concerned with coping (i.e., rebuilding) and resilience, while many engineers orient their practices to adaptation over the long useful life of infrastructure and other improvements. As a rhetorical proposition, this makes sense in that communities and politicians are incentivized to preserve the status quo of their representative constituencies. Likewise, the costs of transformation under adaptation go against the tendencies of public policy to promote stability. However, it can be argued that all constructions of urbanity are in a constant and dynamic state of change. To this end, the rhetorical use of resilience to promote the interests and operations of the status quo may perpetuate structural inequalities which reinforce existing power regimes which are often less than truly progressive in their inefficient allocation of resources and are likely serving maladaptive ends over the long term.

By contrast, the progressive implication of a superior state of flexibility imparted by adaptation is the highest order of outcome among the concepts. While conflicts may arise by and between the concepts, in a perfect scenario the manifestation of a capacity to cope, to mitigate and to be resilient can work in parallel with the advancement of adaptation. Again, adaptation is about periodic points of resiliency which are maintained by a capacity to transform across domains in order to perpetuate resiliency when the resiliency threshold is crossed. However, adaptation is not an ideology defined by the rhetoric of resilience 
but a process which is open to willful engagement. Preserving the status quo in a building through resilience or mitigation alone may not be desirable over the long term, as the modification of behavior based on external influences (i.e., external designs) whether environmental, social or economic, may require radical transformation through the recapitalization and use of a building. If buildings are exclusively designed to be resilient by an existing internal logic then the chance of failure (i.e., reduction in resiliency threshold) is increased as the pace and diversity of change is accelerated with climate change. Therefore, while the transformation associated with adaptation from one regime to another will impart costs, those costs are assumed to be less than the cost of complete failure beyond the resiliency threshold. Although, if one were to think about the broader adaptation of cities, then the failure of a building which has reached its resiliency threshold may be a desirable outcome in that capital may be more efficiently allocated elsewhere.

\section{DEVELOPING A FRAMEWORK FOR BUILDINGS: OBJECTS AND PEOPLE}

The scalability of adaptation measures has been a critical barrier to the generalizable outcomes of the applied systematic study of adaptation (Cash and Moser 2000; Adger et al. 2005; Ostrom 2010). Within the built environment, crossing scales very often amplifies complexities and highlights the tensions between a diversity of actors and interests. For example, if an individual owner elects to build an integrated flood protection system (IFPS) at the scale of his or her building, this is an act of mitigation and resilience as it prevents the building from flooding and maintains the operations of the status quo. Over time, this may or may not lead to adaption. For instance, if a number of individual owners build IFPS for their individual buildings then it might lead to a situation of maladaptation wherein flood waters are redirected to properties which might not have otherwise been flooded. So, what is resilience at one scale might be maladaptation at another.

To date, the study of adaptation has almost exclusively been oriented to the scales of organisms and ecosystems (Schluter 2009; Mawdsley et al. 2009; Losos 2010); local cultures (O'Riordan and Jordan 1999; Adger et al. 2009); business organizations (Nitkin et al. 2009; Linnenluecke et al. 2013); institutions (Næss et al. 2005; Agrawal 2010); local governments (Wilson 2006; Measham et al. 2011); and national and international governments and organizations (Luterbacher and Sprinz 2001; Aldy and Stavins 2007; Giddens 2009; Rübbelke 2011). The scale of buildings has been unexplored as an object of adaptive action and planning. One explanation for this oversight is perhaps an assumption that an examination of local public policies (e.g., building code, land use and environmental regulations) serves as an appropriate scale of inquiry because the policies result in the actualization of buildings which represent the value sets latent in the policies. However, as a practical matter, this is generally not the case even in the most sophisticated jurisdictions as there are economic and social variables associated with building design which escape the comprehensiveness of local public policy that is generally concerned with life and safety considerations which are set as minimum standards (i.e., flooding, systems continuity, ingress/ egress, etc.) (Barton 2014).

Beyond the decisions and influences which impact the nature of the intent to design and manage a building, the building itself represents a hybrid composition for objectification because of the duality of its material form and the social construction of its design, use, management and interpreted meaning or symbolism. In its material manifestation, a building represents a very clear delineation of a formal system with parameterized inputs and outputs, with building systems comprising an independent field of study. At the same time, its social utility defined by program is boundless not as a system with defined parameters but as a social construct, or even an institution, which is ever evolving and constrained only by its own historic path dependencies (North 1990; Thelen 1999). While some institutions within the built environment may be composed of systems of organizations, others may not. The endless variability in the nature of shelter suggests that the institutions of tenancy and tenure-and the management thereof-may be institutions which are not necessarily comprised of clearly defined systems.

As previously noted, adaptation is not just a meta-trajectory of resilience and mitigation measures which preserve the operations of the status quo that over time transforms (or, has the capacity to transform) to a superior progressive state which maintains the ability to be resilient to known stimuli. It is also about a capacity within that superior state to be flexible in addressing (un)known or (un)anticipated stimuli. Therefore, the question is whether one applies theories of adaptation which are grounded: (i) in science oriented towards buildings as technological systems; or, (ii) in social science oriented towards designers, owners, operators and users. Alternatively, is there a certain hybridity which creates a hierarchy or panarchy of processes for evaluating resilience and adaptation? Are these inquires ontologically grounded in the fiction of the building as an objective anthropogenic bystander (or, objective owner) or are they grounded in the realities of subjective multi-generational users, managers and owners? The answer to this fundamental problematique is seemingly clear cut. Buildings themselves do not innately adapt without the intent and action of man. Therefore, adaptation of buildings is a behavior which should be evaluated in the domain of social sciences.

However, this perspective may not be so clear cut in light of the technological innovations in software and hardware design which have empowered an artificial intelligence in building systems to measure, register and adapt to environmental and user generated stimuli (Hayes-Roth 1995; Byun and Park 2011; Bai and Huang 2012; Kumar et al. 2013). As previously noted, adaptation is both a process and a deliberate willful imposition on a process set in motion by a combination of internal and external designs. Therefore, a building as an object may be taught to adapt-or, conversely, it may learn to adapt (Brand 
1995). As internal operations of a software design are updated and reconfigured based on external designs, the likelihood of adaptation increases with the increase in pre-designed simulations which accommodate an increasingly diverse range of stimuli. There may even be a future wherein some vast majority of stimuli (e.g., floods, heat waves, biological terrorism, etc.) are simulated within a reconfiguration of the software based on technologically expanding operational domains (i.e., mechanical, financial, etc.). Therefore, while the degree of willfulness vis-à-vis the intent of the software engineer may vary in time and space, the building as an object may possess a certain requisite artificial intelligence necessary for ex ante adaptation, in addition to ex post adaptation. In this case, ex post adaptation of buildings is the point for reconfiguration or updating of the software following occurrences which are outside of the domains of the building's software. Admittedly, at present, there are functions of buildings which elude measurement and system automation. However, it is possible to envision a future in which every facet of operations, maintenance and capitalization are tactically and strategically evaluated and executed by an integrated computational platform subject to human judgment. With automated valuation models and the MERS system, an integrated artificially intelligent building may even have the capacity to mortgage itself one day. ${ }^{1}$

The other end of the spectrum is the social construction of buildings which are composed of people, organizations and institutions which manage and use the material form. Adaptation can further be refined to be the object of not just climate change in its physical manifestation but also the variability and uncertainty inherent in the concept itself (Smith et al. 2000, p. 227; Hallegatte, 2009). Uncertainty is an innately human characteristic. The origin of the process of adaptation can either be "autonomous" (i.e., automatic, spontaneous, passive or natural) or "planned" (i.e., deliberate, strategic or active) (Smith et al. 2000, p. 239). In the only published paper on the adaptive capacity of real estate developers, Hertin et al. (2003) cite three variations of the theoretical application of adaptation measures by individuals and/or organizations. First, there is the 'Dumb Farmer' hypothesis, in which no adaptation is undertaken at all. Second, there is the hypothetical "ex post" (or, efficient) adaptation strategy which "occurs only after the costs of not adapting have become apparent" (ibid., p. 279). Finally, there is the "Clairvoyant Farmer" hypothesis, or "ex ante" adaptation, which dictates that the host will undertake near perfect measures to adjust to expected future change. The authors argue that these divisions do not necessarily reflect how businessesnotably building developers and owners-actually operate.

It could be argued that organizations that fall into the Dumb Farmer category would eventually go out of business, as they have to position themselves within markets which are in a constant state of adaptation. This assumes that markets at least partially internalize and transfer the cost of climate change. Likewise, it seems unlikely that any business-or building owner/manager-

1 This is perhaps the most extreme example of "robo-signing." would have the requisite intelligence and resources to anticipate the existence or occurrence of a wide range of potential stimuli and undertake perfect ex ante adaptation. However, an artificially intelligent building system with a capacity to iteratively respond to thousands of stimuli might have the capacity to undertake ex ante adaptation-or something very close to it. This ex ante adaptation would theoretically be considered autonomous by virtue of its automatic response; not subject to human strategy and deliberation imbedded in the exercise of a plan in the conventional sense. However, this distinction is not entirely clear cut in that strategic human intervention would arguably be designed within the software. In this sense, the distinction is about execution and not intent.

However, the reality is much more complex. Even as a building system autonomously adapts ex ante, some measures would require human judgment which may be less than informed and the outcome of which may be less than logical. Likewise, those actions may be subject to a historical plan of adaptation or resilience which is less analytically sophisticated than the building's software. This is only one scenario, as the inverse could also be true. Fankhauser et al. (1999) noted that the relationship between autonomous and planned adaptation could be framed as a matter of economy. The measures could be 'complementary' in that "[planned] adaption increases the marginal benefit of [autonomous] and vice versa" (p. 70). For example, a planned measure to change acquisitions strategy away from flood prone buildings may increase the marginal utility of autonomously imposing flood gates on the limited number of existing buildings in one's portfolio. The expensive unit costs of flood gates may not have a reasonable return on investment (i.e., lower insurance premiums or deductibles) for the entire portfolio, but may have a greater utility in a limited number of select buildings. The other linkage between autonomous and planned adaptation measures is that of 'substitute' measures (ibid.). In this scenario, planned measures may completely substitute autonomous measures. Substitutes are more capital intensive and are based on a relative confidence of occurrence which makes their pure application somewhat suspect as a practical matter. As such, Fankhauser et al. suggest that there is balance between these two which are in constant flux as information, vulnerability and general capacity change and evolve.

This balancing act is precisely the nature of the aforementioned duality of buildings. In practice, a building might have its own autonomous adaptive capacity to learn and take action through software reconfiguration, but it is also subject to the human judgment of an owner and/or operator who generally undertakes, in the best case scenario, planned and ex post adaptation. As represented in Diagram 1, intelligence and beliefs within an organization are a critical component of adaptive capacity within a social construct-in this case firms which are a proxy for owners, users and managers (Fankhauser et al. 1999, Hertin, et al. 2003; Berkhout et al. 2004; Arnell and Delaney 2006). The capacity to gather, filter and interpret data both as an 


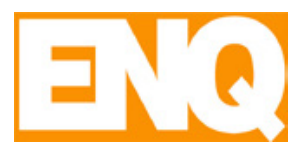

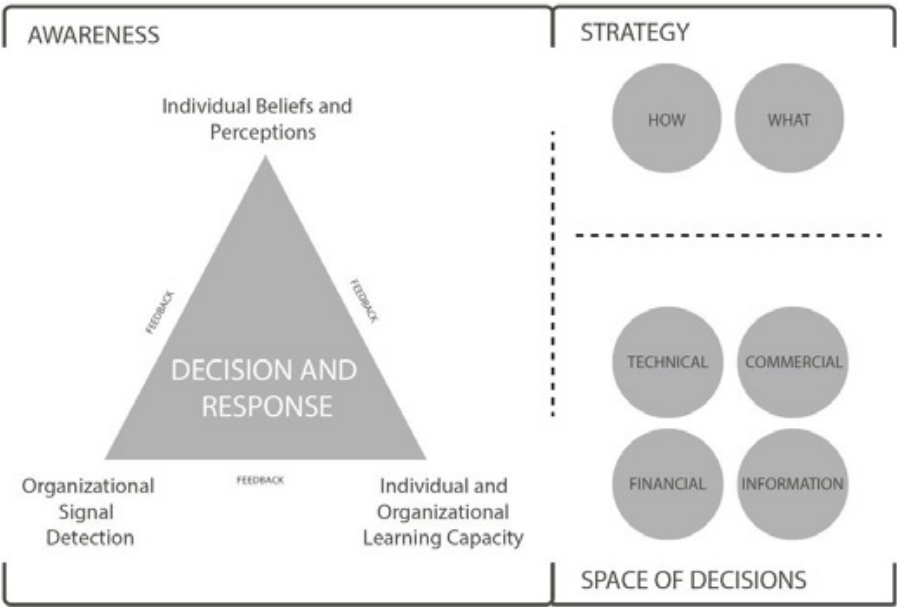

Diagram 1: Framework for Adaptive Capacity of Firms (Users/

Managers). Source: Berkhout et al. (2004); Arnell and Delaney (2006); Fankhauser et al. (1999)

individual and within an organization are dynamically related to and reciprocally dependent on both strategy development and the space of decisions from which they can act with the intent to be resilient and/or adaptive. A recent study of commercial real estate firms in New York City found that corporate and building level strategies were entirely ex post and resulted in planned measures (Keenan 2014). There were no observed actions or strategies which could be defined as autonomous or ex ante. Likewise, it was determined that the adaptive capacity of subject firms was largely driven by human and organizational intelligence (ibid.)

As a consequence of the duality of buildings, there is also a certain duality of adaptive capacity. Buildings as objects have the potential for an autonomous ex ante capacity, as per Diagram 2. Instead of beliefs and organizational intelligence-gathering leading to strategies, the artificial intelligence of buildings operationalized by measuring and reconfiguring the operations of systems leading to, and responsive of, simulations based on a domain of operations, which itself is subject to re-registration. In both capacities, the underlying intent is to recognize, process and respond to stimuli based on a complex set of values.

This relationship (i.e., ex post v. ex ante or top-down v. bottomup) highlights a critical debate within adaption scholarship as to whether there is a hierarchy or a panarchy of influence in stimulating adaptive cycles within systems (Gunderson and Holling 2002; Walker et al. 2006; Gotts 2007; Allen et al. 2014). Systems have been observed to go through fairly predictable cycles of growth, development and decay. In an adaptive cycle, elements of a system interact at various scales to propel a system across phases of exploitation $(r)$, conservation $(k)$, release $(\Omega)$ and reorganization $(\alpha)$ (see Diagram 3) (Holling 1986). While it is not opined that all social, material and ecological phenomena are reducible to systems theory, there is an argument to be

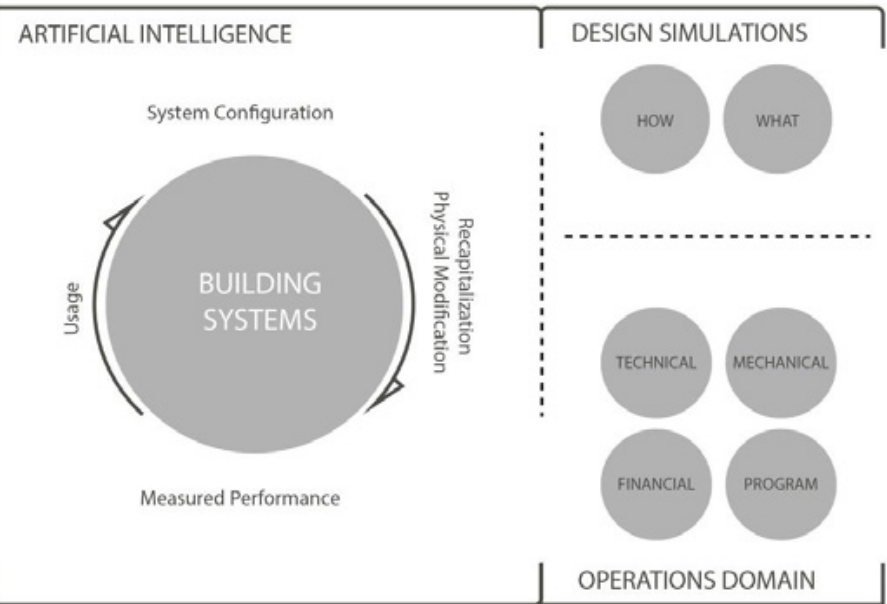

Diagram 2: Framework for Adaptive Capacity of Buildings (Objects)

made that the design, production, and technical operation of buildings fall within clear parameters of one or several systems with discrete inputs and outputs. Likewise, it can analogized that buildings are subject to adaptive cycles often aligned with component life and financial cycles, as represented in Diagram 3. For instance, the perpetuation of the operations of the status quo, or resiliency, are occurring within the conservation (k) phase. The recapitalization of increasingly adaptive building happens in the reorganization $(\alpha)$ phase following the negative effects of stimuli during the release $(\Omega)$ phase. The high point in the efficiency and productivity of the building in terms of use and capital accumulation occurs during the exploitation $(r)$ phase, at which point capital may exit the cycle (i.e., sale or mortgage refinancing).

The conventional Theory of Hierarchy is that there are large slowmoving variables of influence and small fast-moving variables

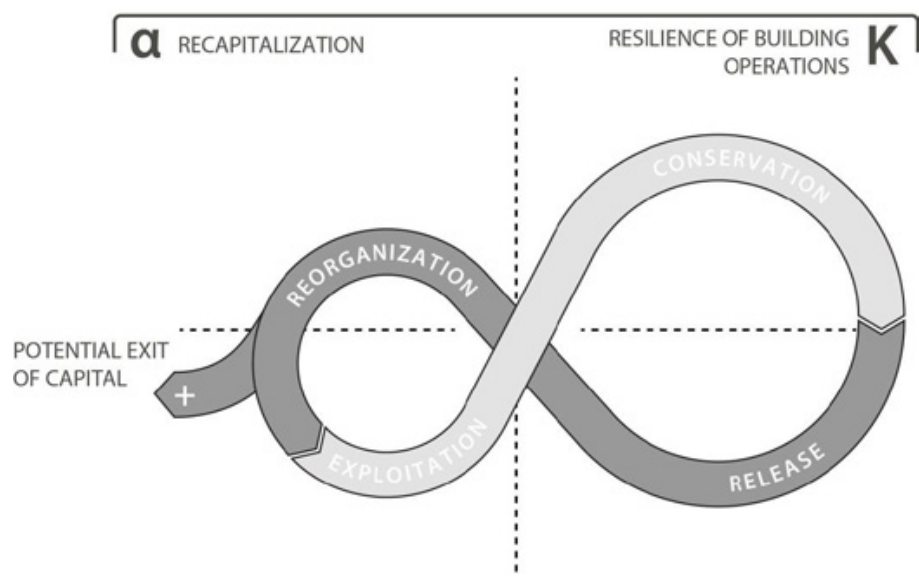

Diagram 3: Building Adaptation Cycle under Theory of Panrchy 
(Allen and Starr 1982; Simon 1991; Brand and Jax 2007, Figure 1 ). As such, a stable system regime is a state mediated between the fast and slow variables which resist and promote change, respectively. It has been theorized that the top-down slow variables create restraints on the fast variables below them. As Gibson et al. note, "[t]he levels immediately above and below the referent level provide environmental constraints and produce a constraint 'envelope' in which the process or phenomenon must remain" (2000, p. 225). This theory has been challenged on numerous grounds, with the principle critiques being that complex systems often operate in non-linear dimensions of time and space and that cause and effect across scales is empirically troublesome to isolate in an intermediate state of analysis (ibid.)

In contrast, the prevailing Theory of Panarchy argues "that control is not just exerted by larger-scale, top-down processes, but can also come from small scale or bottom-up processes. ... Because of the potential for cycling within adaptive cycles to affect both smaller scales and larger scales, panarchy theory emphasizes cross-scale linkages whereby processes at one scale affect those at other scales to influence the overall dynamics of the system" (Allen et al. 2014, p. 578). ${ }^{2}$ This is precisely the nature of the continuous linkage along points of the adaptation cycle as represented in Diagram 3. While top-down design and management of buildings is subject to social, organizational and institutional processes, the realized adaptation cycle of buildings is also subject to ground-up autonomous processes from the building as artificially intelligent object. These processes link across scales and reciprocally influence their respective capacities, as represented in Diagram 4.

It is helpful to conceive of two types of stimuli in the framework. The first set are unrecognized stimuli which may be social, environmental and/or economic in their origins. The second set of stimuli are those which have been intelligently processed based on the respective dual capacities. For example, information from a building system may indicate where along the adaptation cycle the building is so as to inform a corporate portfolio strategy which may in turn dictate the capitalization of a related building system that results in greater realized adaptation along the reorganization $(\alpha)$ phase. Without the artificially intelligent system to translate unrecognized stimuli to recognized stimuli, this sort of outcome is less likely in terms of realized adaptation. More precisely, artificial intelligence leads to mitigation and resilience-even homeostasis-in the short term. What makes it adaptive is its capacity to simulate and recognize stimuli which are unanticipated by human and/or organizational capacities and which themselves can be reconfigured as circumstances evolve. To this end, the framework links capacities with realized adaptation as positioned within the adaptive cycle of a building which is driven by a variety of intelligent and unrecognized stimuli.

2 For the application of Panarchy Theory to urban systems, see Bessey (2002); Garmestani et al. (2005); Garmestani et al. (2008).

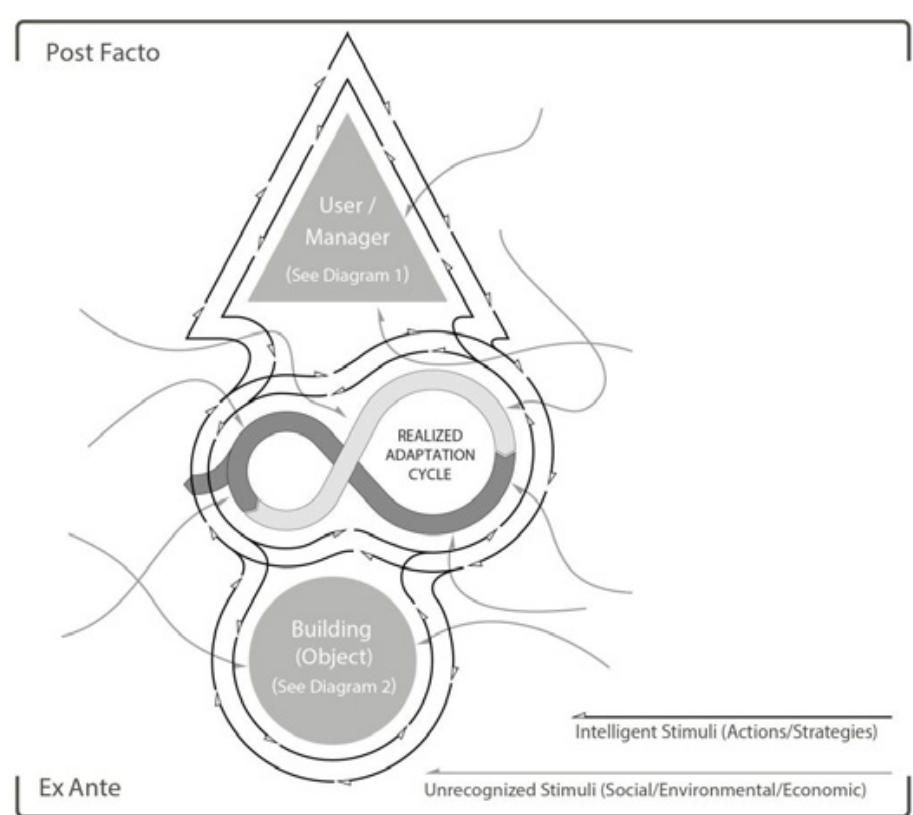

Diagram 4: Framework for Multiscalar Dynamic Adaptation of Buidlings

Together these processes, which are made up of multiple subprocesses, are dynamically interlinked across scales. Therefore, it would be a gross simplification, for example, to argue that financial investment criteria will exclusively dictate adaptation of buildings in the future, as is the present dominant rationality of mitigation and sustainability. Financial criteria may have a principle influence on the capacity and actions of the topdown processes of an owner/operator organization but are not necessarily determinate of the bottom-up capacities which may or may not themselves be determinate of the long-term realized adaptation of a building. In this sense, realized adaptation is the actual adaptation which is subject to bottom-up and top-down processes. This doesn't mean that there is equal weighting of influence from these differing modes of adaptation (capital may still dominate realized adaptation, for instance), but it acknowledges a more dynamic system of influences which itself has the capacity to adapt as technology and innovation respond to change. Therefore, the capacity of a building is composed of the two sub-capacities identified in Diagrams 1 and 2 and whose sum is greater than its parts, assuming the non-occurrence of maladaptation.

Finally, it should be cautioned that this system of adaptive capacity can also promote maladaptation. While a robust capacity may increase the likelihood of adaption, there may be forces at work, willful or otherwise, which may reduce capacity to a point which results in a state of maladaptation. As one moves out of the built environment and beyond the scale of the building, it also worth acknowledging that adaptation of buildings may conflict with other societal responses to climate change. For instance, if the global real estate community in cities subject to high risk of 
flooding were to fortify their buildings with more concrete and steel, then the energy, resources and pollution expended in this effort might conflict with climate mitigation goals and might draw resources away from other modes of societal adaptation. As such, this framework should be contextualized across urban, regional and global scales to give meaning not to its inherent utility but to the implications of the broader impacts of the adaptation of buildings.

From the designer's point of view this complexity underscores the necessity to frame the design and operation of buildings within a complex array of processes with varying levels of human and artificial intelligence. A fundamental aspect of the concept of adaptation is an ability to be flexible while traversing a state of transformation. Transformation may manifest itself in everything from changing programs (i.e., from hospitality to senior housing) to the intensity of existing uses. The conventional problem set of designing flexible interiority to a building to accommodate future alternative programs is just one of several exercises in conceiving of a comprehensive design (Sinclair et al. 2012). In this sense, interior adaptability is just a method within adaptation. Architecture has struggled with adaptation, as demonstrated by several generations of failed experiments in modularity. However, there is an opportunity to develop practices in adaptive design beyond the rules of thumb for open plans, durable materials, passive systems, low maintenance and accommodation for future expansion.

As such, thinking about how a building is used and operated and how those criteria can be measured to inform both artificial and human intelligence will be critical in the future. Likewise, having a sensitivity beyond the physicalities of the building to understand management processes and their influence on the intermediate resilient state of operations is also critical to contextualizing design within human and environmental conditions. Each of these scales and sensitivities require facility in a variety of skills and disciplines, including architecture, process engineering, computer science, real estate development, urban planning, facilities planning, material science, operations planning and a multitude of other disciplines. This requisite diversity of knowledge reinforces the notion that professional practices within the built environment are both an art and a science-or, in this case, social science. Ultimately, one or several professions will need to be positioned to mediate language and values by and between the various disciplines in the advancement of adaptation. Will this be the role of the architect?

\section{EXPLANATORY SCENARIO WITHIN FRAMEWORK}

It should be acknowledged that a number of key architectural figures in recent history, such as Buckminster Fuller, Christopher Alexander and Frank Duffy, have endeavored to synthesize these varying domains of knowledge into an contemporary architectural discourse. However, it is the work of Stewart Brand, notably in How Buildings Learn: What Happens After They're Built (1995), which heavily influences the application of the framework developed in this paper. Brand's perspective on the adaptation of buildings was one grounded in the necessity to develop internal designs which can accommodate inevitable human adaptations. Brand went so far as to draw reference to a Theory of Hierarchy in his own work in that he conceptualized fast bottom-up and slow top-down influences-largely social and economic (p. 17). However, with a measure of clarity not quite ripe at the time, he tempered that conceptualization by citing Holling and the theoretical extent to which fast and slow variables may shift hierarchical functions across scales (i.e., consistent with panarchy) (ibid.). In many ways, the framework developed herein picks up where Brand left off in that it accounts for technologies-adaptive censors and buildings systems and their associated modes of artificial intelligence-which simply did not exist at the time of Brand's research.

Therefore, the questions are: (i) what are some of the existing adaptive technologies; and, (ii) how could they be referenced to explain the framework of adaptation? By example, currently, adaptive lighting, ventilation, façade and energy management systems are being developed and selectively utilized in the U.S. (Hoberman and Schwitter 2008; Erikson 2013; Hansen 2013). These systems are being utilized in new buildings, which likely will be subject to changing climatic conditions in the future. One example of adaptation is a scenario wherein the energy management system measures the performance of the other systems and forces calibration on the time and mode of use so as to promote energy efficiency. This serves to both mitigate the risks of overconsumption, for instance on hot days, and it is adaptive because it forces utilization of the building systems beyond their initial configured domains of operation. Likewise, the energy management system outputs could also be adaptive to the extent that building managers utilize the outputs of the energy management system to inform tenant use (e.g., incentivize night-time super-computing).

In this scenario, as excessively hot days occur more frequently, let's assume the mechanical façade systems are being utilized beyond their intended design for durational stress and the façade system malfunctions. The building owners and managers now have to decide whether the capital costs for fixing or upgrading the façade system justify the amortized return on investment relative to the modeled reduction in energy costs. In this scenario, the owners and managers decide that the replacement costs far exceed their benchmark for amortized returns. They also realize that by reallocating some fraction of the façade replacement cost to upgrading the software configuration for the other systems they will be able to realize a net efficiency gain. The scenario could be extended to assume that thirty years later the supercomputing tenants no longer remain and the building transforms programs (i.e., domains) to accommodate tenants with much lower energy consumption. At a point in time when the life cycles of the original lighting and ventilation systems require a similar evaluation under a cost-benefit analysis, it is determined that both systems justify recapitalization because the reduction 
in energy use from newer more efficient tenants doesn't offset the greater demands from ambient, radiant and convective heat caused by global warming.

The realized adaptation at each stage could have only been accommodated with this measure of precision and corresponding efficiency with the benefit of outputs from the artificially intelligent building systems and the judgments of the owners and managers, which were informed in some measure by the artificial intelligence. The question then is could adaptation have happened without these intelligent building systems? Yes, the owners could have kicked out all of the super-computing tenants to reduce their energy burden. However, the high priced rents the super-computing tenants would have paid could have resulting in lower levels of overall capitalization, resulting in a shorter life cycle of the building. In either event, the scenarios for adaptation and maladaptation are nearly endless in their manifestations one way or the other. The framework in this paper only reinforces the capacities of users and managers, who will never be completely substituted in their judgments by artificially intelligent buildings. It is likely not possible nor is it desirable that such substitution take place given that buildings ultimately serve the interests of human habitation. If buildings were truly artificially intelligent, then it is likely that humans would be excluded from occupancy in the advancement of adaptation. The advantage of this framework is that it sets the stage for developing more robust human capacities, which promotes the effective, efficient and timely allocation of resources along the adaptation cycle of a building with the intent of maximizing the probability occurrence of adaptive versus maladaptive outcomes.

\section{CONCLUSIONS AND FUTURE RESEARCH}

The academy of architecture has long struggled to manage complexity without succumbing to the external parametric applications of systems theory. While not explicit, one could argue that this reservation has been grounded in a variant Theory of Hierarchy wherein influences outside of the hand of the architect are dictating aesthetic and programmatic gestures which dilute-or more formally limit-the creative capacities of architecture, which sits within a hierarchy of capital and culture. It is not a coincidence that architecture complains of the limitation of the "envelope." Must applied systems theory in architecture be reduced to an architecturally void "technological sublime"? (Wolfe 2006, p. 5). At the same time and at a different scale, hierarchy has been deemed, with all of its classical sensibilities, to be the Third Law of Structural Order (Salingaros and Mehaffy 2006; Tracada 2013). However, this rhetorical tension is largely one of aesthetics and itself represents a certain panarchy of influence between the ordered, random and chaotic gestures of architectural expression.

But, analysis and expression are process and outcome. While this division is not so clear in light of the aestheticization of data visualization and the practice of improvisation, it highlights the role of the framework developed herein as analytical with very limited generative applications. This is perhaps both a strength and a weakness. But, this framework fits within an analytical theory of architecture which acknowledges the practice as both an art and a science (Hillier 1999). At best, its implications are for propelling the professional domain into realms of intelligence and knowledge which modify workflows and processes to accommodate changing conditions. While the current set of professional ethics apply to the lawful state of construction of a building on day one-would or should that ethic be extended throughout the building's useful life? At worst, it is a framework which is not quiet ripe in light of the current reality of buildings which are not so intelligent. To this end, it serves as a challenge to give greater dynamic consideration to the autonomy of the building as an object-albeit a systemized object.

By giving resolution to the dual capacities of human and artificial intelligence of a building defined by its material and social construction, the framework for the dynamic multi-scalar adaptation of buildings draws a nexus between the adaptation cycle of a building and the varied social, economic and environmental forces which are shaping the built environment. Ultimately, artificial intelligence serves not only as an adjunct for human judgment but as a powerful barometer of unrecognized stimuli. The future development of this framework will be advanced by case studies which inquire as to the nature of the decisions which frame the selection, operation and recapitalization of adaptive building systems. Thereafter, the framework could be advanced by understanding the methodologies associated with these decisions along varying trajectories of the adaptation cycle as mediated by the dual modes of intelligence (Wilkinson et al. 2014). Implicit in this exercise is an elucidation of the values which speak to the weighting of priorities for the allocation of limited resources.

Future research in architectural technology could therefore explore how technology is actually interpreted and utilized by owners and operators. To this end, research could be extended to give consideration to positive behavioral modification through not only conventional building systems but latent and patent spatial constructions-which themselves may be systematized in the future. Deeper explorations of technology would serve not just efficiency-seeking ends but are themselves reconfigurable to changing conditions wherein efficiency in one state might be inefficient in another. Research into various simulations which are responsive to a litany of stimuli which are configurable to a mode of action is a task with no end in light of a world subject to constant and accelerated change. Ultimately, this framework for adaptation acknowledges a duality of material and social construction in buildings which is ripe for the appropriation of developments in scientific and social scientific knowledge in the willful steering of adaptation cycles which are informed by natural and artificial modes of intelligence. In this context, design research is uniquely positioned to further develop synthetic lines of knowledge which are responsive to a world defined by conflicting realities grounded in art, science and social science. 
Architects and the society which they serve cannot afford to be the 'dumb farmers' any longer.

\section{REFERENCES}

Adger, W. Neil, Nigel W. Arnell and Emma L. Tompkins. "Successful Adaptation to Climate Change Across Scales." Global Environmental Change 15.2 (2005): 77-86. Print.

Adger, W. Neil, Suraje Dessai, Marisa Goulden, Mike Hulme, Irene Lorenzoni, Donald R. Nelson, Lars Otto Naess, Johanna Wolf and Anita Wreford. "Are There Social Limits to Adaptation to Climate Change?" Climatic Change 93.34 (2009): 335-354. Print.

Agrawal, Arun. "Local Institutions and Adaptation to Climate Change." Social Dimensions of Climate Change: Equity and Vulnerability in a Warming World. Robin Mearns and Andrew Norton, eds. Washington, DC: World Bank (2010): 173-198. Print.

Aldy, Joseph E., and Robert N. Stavins, eds. Architectures for Agreement: Addressing Global Climate Change in the Post-Kyoto World. Cambridge: Cambridge University Press, 2007. Print.

Allen, Craig R., David G. Angeler, Ahjond S. Garmestani, Lance H. Gunderson and C.S. Holling. "Panarchy: Theory and Application." Ecosystems 17.4 (2014): 578-589. Print.

Allen, Timothy F.H., and Thomas B. Starr. Hierarchy: Perspectives for Ecological Complexity. Chicago: University of Chicago Press, 1982. Print.

Anderson, Tom. Resilient Computing Systems: Vol. 2. New York: John Wiley \& Sons, 1988. Print.

Arnell, Nigel W., and E. Kate Delaney. "Adapting to Climate Change: Public Water Supply in England and Wales." Climatic Change 78.2-4 (2006): 227-255. Print.

Bai, Zhi-yong, and Xin-yuan Huang. "Design and Implementation of a Cyber Physical System for Building Smart Living Spaces." International Journal of Distributed Sensor Networks (2012). n.pag. Web. 15 March 2012. [http://www.hindawi.com/journals/ ijdsn/2012/764186/abs/]

Barton, Cynthia. Personal Interview. June 17, 2014.

Berkhout, Frans, Julia Hertin and Nigel Arnell. "Business and Climate Change: Measuring and Enhancing Adaptive Capacity." Technical Report 11. Tyndall Centre for Climate Change, University of South Hampton (2004). Web. [http://www.tyndall.ac.uk/ sites/default/files/Berkhout,\%20F.,\%20Hertin,\%20J.\%20and\%20 Arnell,\%20N.\%20(2004)\%20Business\%20and\%20Climate\%20 Change $\% 20-\% 20$ Measuring $\% 20$ and $\% 20$ Enhancing $\% 20$ Adaptive\%20Capacity\%20(tr11).pdf]
Bessey, K. Michael. "Structure and Dynamics in an Urban Landscape: Toward a Multiscale View." Ecosystems 5.4 (2002): 360-375. Print.

Brand, Fridolin Simon, and Kurt Jax. "Focusing the Meaning(s) of Resilience: Resilience as a Descriptive Concept and a Boundary Object." Ecology and Society 12.1 (2007): 23. Web.

[http://www.ecologyandsociety.org/vol12/iss1/art23/]

Brand, Stewart. How Buildings Learn: What Happens After They're Built. New York: Penguin, 1995. Print

Brown, Lance Jay, and David Dixon. Urban Design for an Urban Century: Shaping More Livable, Equitable, and Resilient Cities. Hoboken, NJ.: John Wiley \& Sons, 2014. Print.

Bulkeley, Harriet, and Michele M. Betsill. "Revisiting the Urban Politics of Climate Change." Environmental Politics 22.1 (2013): 136-154. Print.

Byun, Jinsung, and Sehyun Park. "Development of a Self-adapting Intelligent System for Building Energy Saving and Context-aware Smart Services." Consumer Electronics, IEEE Transactions 57.1 (2011): 90-98. Print.

Cash, David W., and Susanne C. Moser. "Linking Global and Local Scales: Designing Dynamic Assessment and Management Processes." Global Environmental Change 10.2 (2000): 109-120. Print.

Cohen, Stewart, David Demeritt, John Robinson and Dale Rothman "Climate Change and Sustainable Development: Towards Dialogue." Global Environmental Change 8.4 (1998): 341-371. Print.

Erikson, James. Envelope as Climate Negotiator: Evaluating Adaptive Building Envelope's Capacity to Moderate Indoor Climate and Energy. Diss. Arizona State University, 2013. Tempe: ASU, 2013.

Etzion, Y., D. Pearlmutter, E. Erell and I.A. Meir. "Adaptive Architecture: Integrating Low-energy Technologies for Climate Control in the Desert." Automation in Construction 6.5 (1997): 417-425. Print.

Fankhauser, Samuel, Joel B. Smith and Richard S.J. Tol. "Weathering Climate Change: Some Simple Rules to Guide Adaptation Decisions." Ecological Economics 30.1 (1999): 67-78. Print.

Garmestani, Ahjond S., Craig R. Allen and K. Michael Bessey. "Time-series Analysis of Clusters in City Size Distributions." Urban Studies 42.9 (2005): 1507-1515. Print. 
Garmestani, Ahjond S., Craig R. Allen, and Colin M. Gallagher. "Power Laws, Discontinuities and Regional City Size Distributions." Journal of Economic Behavior \& Organization 68.1 (2008): 209216. Print.

Gibson, Clark C., Elinor Ostrom and Toh-Kyeong Ahn. "The Concept of Scale and the Human Dimensions of Global Change: a Survey." Ecological Economics 32.2 (2000): 217-239. Print.

Giddens, Anthony. The Politics of Climate Change. Cambridge, UK: Wiley, 2009. Print.

Givoni, Baruch. Climate Considerations in Building and Urban Design. New York: John Wiley \& Sons, 1998. Print

Goklany, Indur M. "A Climate Policy for the Short and Medium Term: Stabilization or Adaptation?" Energy \& Environment 16.3 (2005): 667-680. Print.

Gotts, Nicholas M. "Resilience, Panarchy, and World-systems Analysis." Ecology and Society 12.1 (2007): 24. Print.

Gunderson, Lance H., and Crawford S. Holling, eds. Panarchy: Understanding Transformations in Systems of Humans and Nature. Washington, DC: Island Press, 2002. Print.

Hallegatte, Stéphane. "Strategies to Adapt to an Uncertain Climate Change." Global Environmental Change 19.2 (2009): 240-247. Print.

Hamel, Gary, and Lisa Valikangas. "The Quest for Resilience." Harvard Business Review 81.9 (2003): 52-65. Print.

Hansen, Kai L. "The Development and Valuation of Intelligent and Adaptive Building Systems." The Visibility of Research: Proceedings of the Spring 2013 Architectural Research Centers Consortium, University of North Carolina Charlotte, March 2730, 2013. Chris Jarrett, Kyoung-Hee Kim and Nick Senske, eds. Charlotte, NC: University of North Carolina, Charlotte, (2013): 491-499.

Hayes-Roth, Barbara. "An Architecture for Adaptive Intelligent Systems." Artificial Intelligence 72.1 (1995): 329-365. Print.

Hertin, Julia, Frans Berkhout, David Gann and James Barlow. "Climate Change and the UK House Building Sector: Perceptions, Impacts and Adaptive Capacity." Building Research \& Information 31.3-4 (2003): 278-290. Print.

Hillier, Bill. Space is the Machine: A Configurational Theory of Architecture. Cambridge, UK: Press Syndicate of the University of Cambridge, 1999. Print.
Hoberman, Chuck, and C. Schwitter. "Adaptive Structures: Building for Performance and Sustainability." Design Intelligence (August 11, 2008). Print.

Holling, Crawford S. "Resilience and Stability of Ecological Systems." Annual Review of Ecology and Systematics (1973): 1-23. Print.

Holling, Crawford S. "Resilience of Ecosystems: Local Surprise and Global Change." Sustainable Development of the Biosphere. W.C. Clark and R.E. Munn, eds. Cambridge, UK: Cambridge University Press, 1986. 292-317. Print.

[IPCC 1996] Arrow, K.J., J. Parikh, G. Pillet, M. Grubb, E. Haites, J.C. Hourcade, K. Parikh and F. Yamin. "Decision-making Frameworks for Addressing Climate Change." Climate Change 1995: Economic and Social Dimensions of Climate Change. J.P. Bruce, H. Lee and E.F. Haites eds. Contribution of Working Group III to the Second Assessment Report of the Intergovernmental Panel on Climate Change. Cambridge, UK: Cambridge University Press, 1996. Print.

[IPCC 2001a] Moomaw, W.R., J.R. Moreira, K. Blok, D.L. Greene, K. Gregory, T. Jaszay, T. Kashiwagi, M. Levine, M. McFarland, N. Siva Prasad, L. Price, H.-H. Rogner, R. Sims, F. Zhou and P. Zhou. "Technological and Economic Potential of Greenhouse Gas Emission Reduction." Climate Change 2001: Mitigation. B. Metz, O. Davidson, R. Swart and J. Pan, eds. Contribution of Working Group III to the Third Assessment Report of the Intergovernmental Panel on Climate Change. Cambridge, UK: Cambridge University Press, 2001. Print.

[IPCC 2001b] Toth, F.L., M. Mwandosya, C. Carraro, J. Christensen, J. Edmonds, B. Flannery, C. Gay-Garcia, H. Lee, K.M. Mayer-Abich, E. Nikitin, A. Rahman, R. Richels, Y. Ruqiu, A. Villavicencio, Y. Wake and J. Weyant. "Decision-making Frameworks." Climate Change 2001: Mitigation. B. Metz, O. Davidson, R. Swart and J. Pan, eds. Contribution of Working Group III to the Third Assessment Report of the Intergovernmental Panel on Climate Change. Cambridge, UK: Cambridge University Press, 2001. Print.

[IPCC 2007a] Parry, Martin L., ed. "Climate Change 2007: Impacts, Adaptation and Vulnerability." Contribution of Working Group II to the Fourth Assessment Report of the Intergovernmental Panel on Climate Change Vol. 4. Cambridge, UK: Cambridge University Press, 2007. Print.

[IPCC 2007b] Parry, Martin L., ed. “Climate Change 2007: 18.1.2 Differences, Similarities and Complementarities between Adaptation and Climate Change." Contribution of Working Group II to the Fourth Assessment Report of the Intergovernmental Panel on Climate Change Vol. 4. Cambridge, UK: Cambridge University Press, 2007. Print. 
[IPCC 2007c] Parry, Martin L., ed. "Climate Change 2007: TS 5.2 Interrelationships between Adaptation and Mitigation." Contribution of Working Group II to the Fourth Assessment Report of the Intergovernmental Panel on Climate Change Vol. 4. Cambridge, UK: Cambridge University Press, 2007. Print.

[IPCC 2014] Edenhofer, O., R. Pichs-Madruga, Y. Sokona, E. Farahani, S. Kadner, K. Seyboth, A. Adler, I. Baum, S. Brunner, P. Eickemeier, B. Kriemann, J. Savolainen, S. Schlömer, C. von Stechow, T. Zwickel and J.C. Minx, eds. "Climate Change 2014: Mitigation of Climate Change." Contribution of Working Group III to the Fifth Assessment Report of the Intergovernmental Panel on Climate Change. Cambridge, UK and New York: Cambridge University Press, 2014. Print.

Keenan, Jesse M. "Adaptive Capacity of Commercial Real Estate Firms in NYC to Climate Change and Urban Flooding." Working Paper, Center for Urban Real Estate. New York: Columbia University (2014). Web. October 13, 2014. [https://www. academia.edu/8239545/Adaptive_Capacity_of_Commercial_ Real_Estate_Firms_to_Climate_Change_in_NYC]

Klein, Richard J.T., E. Lisa F. Schipper and Suraje Dessai. "Integrating Mitigation and Adaptation into Climate and Development Policy: Three Research Questions." Environmental Science \& Policy 8.6 (2005): 579-588. Print.

Kumar, Vikash, Anna Fensel and Peter Fröhlich. "Context Based Adaptation of Semantic Rules in Smart Buildings." Proceedings of International Conference on Information Integration and Webbased Applications \& Services. New York: ACM, 2013. Web.

[http://dl.acm.org/citation.cfm?id=2539174]

Laprie, Jean-Claude. "From Dependability to Resilience." 38th IEEE/IFIP Int. Conf. on Dependable Systems and Networks. 2008. Web. [http://users.ece.cmu.edu/ koopman/dsn08/fastabs/ dsn08fastabs_laprie.pdf]

Lazarus, Richard S., and Susan Folkman. Stress, Appraisal, and Coping. New York: Springer Publishing Company, 1984. Print.

Lee, Amy V., John Vargo and Erica Seville. "Developing a Tool to Measure and Compare Organizations' Resilience." Natural Hazards Review 14.1 (2013): 29-41. Print.

Lempert, Robert J., and Michael E. Schlesinger. "Robust Strategies for Abating Climate Change." Climatic Change 45.3 (2000): 387401. Print.

Linnenluecke, Martina K., Andrew Griffiths and Monika I. Winn. "Firm and Industry Adaptation to Climate Change: a Review of Climate Adaptation Studies in the Business and Management Field." Wiley Interdisciplinary Reviews: Climate Change 4.5 (2013): 397-416. Print.
Losos, Jonathan B. "Adaptive Radiation, Ecological Opportunity, and Evolutionary Determinism." The American Naturalist 175.6 (2010): 623-639. Print.

Luterbacher, Urs, and Detlef F. Sprinz, eds. International Relations and Global Climate Change. Cambridge, MA.: MIT Press, 2001. Print.

Mawdsley, Jonathan R., Robin O'Malley and Dennis S. Ojima. "A Review of Climate-Change Adaptation Strategies for Wildlife Management and Biodiversity Conservation." Conservation Biology 23.5 (2009): 1080-1089. Print.

Mazmanian, Daniel A., John Jurewitz and Hal T. Nelson. "A Governing Framework for Climate Change Adaptation in the Built Environment." Ecology and Society 18.4 (2013): 56. Print.

McEvoy, Darryn, Sarah Lindley and John Handley. "Adaptation and Mitigation in Urban Areas: Synergies and Conflicts." Proceedings of the ICE-Municipal Engineer 159.4 (2006): 185-191. Print.

McNiff, Jean. Action Research: Principles and Practice. London: Routledge, 2013. Print

Measham, Thomas G., Benjamin L. Preston, Timothy F. Smith, Cassandra Brooke, Russell Gorddard, Geoff Withycombe and Craig Morrison. "Adapting to Climate Change Through Local Municipal Planning: Barriers and Challenges." Mitigation and Adaptation Strategies for Global Change 16.8 (2011): 889-909. Print.

Moser, Susanne C., and Julia A. Ekstrom. "A Framework to Diagnose Barriers to Climate Change Adaptation." Proceedings of the National Academy of Sciences 107.51 (2010): 22026-22031. Print.

Næss, Lars Otto, Guri Bang, Siri Eriksen and Jonas Vevatne. "Institutional Adaptation to Climate Change: Flood Responses at the Municipal Level in Norway." Global Environmental Change 15.2 (2005): 125-138. Print.

Nelson, Donald R. "Adaptation and Resilience: Responding to a Changing Climate." Wiley Interdisciplinary Reviews: Climate Change 2.1 (2011): 113-120. Print.

Nelson, Donald R., W. Neil Adger and Katrina Brown. "Adaptation to Environmental Change: Contributions of a Resilience Framework." Annual Review of Environment and Resources 32.1 (2007): 395-419. Print.

Nicholls, Neville. "Cognitive Illusions, Heuristics, and Climate Prediction." Bulletin of the American Meteorological Society 80.7 (1999): 1385-1397. Print. 
Nitkin, David, Ryan Foster and Jacqueline Medalye. A Systematic Review of the Literature on Business Adaptation to Climate Change. Toronto: Network for Business Sustainability, 2009. Web. [nbs.net/fr/files/2011/08/NBS_ClimateChange_Concepts_2009. pdf]

North, Douglass C. Institutions, Institutional Change and Economic Performance. Cambridge, UK: Cambridge University Press, 1990.

O’Riordan, Timothy, and Andrew Jordan. "Institutions, Climate Change and Cultural Theory: Towards a Common Analytical Framework." Global Environmental Change 9.2 (1999): 81-93. Print.

Ostrom, Elinor. "A Multi-scale Approach to Coping with Climate Change and Other Collective Action Problems." Solutions 1.2 (2010): 27-36. Print.

Ovink, Henk. Personal Interview. June 27, 2014.

Preston, Benjamin L., Johanna Mustelin and Megan C. Maloney. "Climate Adaptation Heuristics and the Science/Policy Divide." Mitigation and Adaptation Strategies for Global Change (2013): 1-31. Web. September 5, 2013.

Rübbelke, Dirk T.G. "International Support of Climate Change Policies in Developing Countries: Strategic, Moral and Fairness Aspects." Ecological Economics 70.8 (2011): 1470-1480. Print.

Salingaros, Nikos A., and Michael W. Mehaffy. A Theory of Architecture. Solingen, Germany: UMBAU-VERLAG/Harald Püschel, 2006. Print.

Schluter, Dolph. "Evidence for Ecological Speciation and its Alternative." Science 323.5915 (2009): 737-741. Print.

Schuetze, Thorsten. "Climate Adaptive Urban Design with Water in Dutch Polders." Water Science and Technology 64 (2011): 722730. Print.

Simon, Herbert A. "The Architecture of Complexity." International Federation for Systems Research International Series on Systems Science and Engineering 7 (1991): 457-476. Print.

Sinclair, Brian R., Somayeh Mousazadeh and Ghazaleh Safarzadeh. "Agility, Adaptability + Appropriateness: Conceiving, Crafting \& Constructing an Architecture of the 21st Century." Enquiry/The ARCC Journal of Architectural Research 9.1 (2012): 35-43. Web. [http://www.arcc-journal.org/index.php/arccjournal/article/ view/857663523]

Smith, Barry, lan Burton, Richard J.T. Klein and Johanna Wandel. "An Anatomy of Adaptation to Climate Change and Variability." Climatic Change 45.1 (2000): 223-251. Print.
Steemers, Koen. "Towards a Research Agenda for Adapting to Climate Change." Building Research \& Information 31.3-4 (2003): 291-301. Print.

Stern, Nicholas, ed. The Economics of Climate Change: The Stern Review. Cambridge, UK: Cambridge University Press, 2007. Print.

Sunstein, Cass R. "The Availability Heuristic, Intuitive Cost-Benefit Analysis, and Climate Change." Climatic Change 77.1-2 (2006): 195-210. Print.

Swart, Rob, Robbert Biesbroek and Tiago Capela Lourenço. "Science of Adaptation to Climate Change and Science for Adaptation." Interdisciplinary Climate Studies 2 (2014): 29. Web. July 2, 2014. [http://journal.frontiersin.org/Journal/10.3389/ fenvs.2014.00029/full]

Thelen, Kathleen. "Historical Institutionalism in Comparative Politics." Annual Review of Political Science 2.1 (1999): 369-404. Print.

Tracada, Eleni. "The Fractal Urban Coherence in Biourbanism: The Factual Elements of Urban Fabric." The International Journal of Architectonic, Spatial, and Environmental Design 7.1 (2013): n. pg. Web. September 24, 2013.

[http://hdl.handle.net/10545/302164]

Uittenbroek, Caroline J., Leonie B. Janssen-Jansen and Hens AC Runhaar. "Mainstreaming Climate Adaptation into Urban Planning: Overcoming Barriers, Seizing Opportunities and Evaluating the Results in Two Dutch Case Studies." Regional Environmental Change 13.2 (2013): 399-411. Print.

Vachon, Geneviève, Marie-Noël Chouinard, Geneviève Cloutier, Catherine Dubois and Carole Després. "An Interdisciplinary and Intersectoral Action-research Method: Case-Study of Climate Change Adaptation by Cities Using Participatory Web 2.0 Urban Design." Enquiry/The ARCC Journal of Architectural Research 10.1 (2013): 15. Print.

Van der Linden, A.C., A.C. Boerstra, A.K. Raue, S.R. Kurvers and R.J. De Dear. "Adaptive Temperature Limits: A New Guideline in the Netherlands: A New Approach for the Assessment of Building Performance with Respect to Thermal Indoor Climate." Energy and Buildings 38.1 (2006): 8-17. Print.

Vogus, Timothy J., and Kathleen M. Sutcliffe. "Organizational Resilience: Towards a Theory and Research Agenda." Systems, Man and Cybernetics, 2007. ISIC. IEEE International Conference on. IEEE, 2007. Web.

[http://ieeexplore.ieee.org/xpl/login.jsp?tp=\&arnumber=44141 60\&url=http\%3A\%2F\%2Fieeexplore.ieee.org\%2Fxpls\%2Fabs_all. jsp\%3Farnumber\%3D4414160] 
Walker, Brian, Lance Gunderson, Ann Kinzig, Carl Folke, Steve Carpenter and Lisen Schultz. "A Handful of Heuristics and Some Propositions for Understanding Resilience in Social-Ecological systems." Ecology and Society 11.1 (2006): 13. Print.

Wiggins, Mike. "CEDRA: Climate change and Environmental Degradation Risk and Adaptation Assessment." Tearfund (2009). Web.

[http://tilz.tearfund.org/en/themes/environment_and_ climate/cedra/]

Wilkinson, Sara J., Hilde Remøy and Craig Langston. Sustainable Building Adaptation: Innovations in Decision-Making. Oxford, UK: John Wiley \& Sons, 2014. Print.

Wilson, Elizabeth. "Adapting to Climate Change at the Local Level: the Spatial Planning Response." Local Environment 11.6 (2006): 609-625. Print.

Wolfe, Cary. "Lose the Building: Systems Theory, Architecture, and Diller+ Scofidio's Blur." Postmodern Culture 16.3 (2006). Print.

Woods, David D., and John Wreathall. "Stress-strain Plots as a Basis for Assessing System Resilience." Resilience Engineering: Remaining Sensitive to the Possibility of Failure. E. Hollnagel, C. Nemeth and S.W.A. Dekker, eds. Aldershot, UK: Ashgate, 2008. 145-161. Print. 